\title{
Numerical investigation of in-cylinder flow characteristics of hydrogen-fuelled internal combustion engine
}

\author{
Khalaf I. Hamada', M.M. Rahman'2, D. Ramasamy' ${ }^{2}$,M.M. Noor ${ }^{2}$ \\ and K. Kadirgama ${ }^{2}$ \\ ${ }^{1}$ Department of Mechanical Engineering, College of Engineering, \\ University of Tikrit, Tikrit, Iraq \\ ${ }^{2}$ Automotive Excellence Center, University Malaysia Pahang, \\ 26300 Gambang, Kuantan, Pahang, Malaysia \\ Email: mustafizur@ump.edu.my
}

\begin{abstract}
This paper addresses the computational fluid dynamics (CFD) simulation to investigate the in-cylinder flow characteristics of $2 \mathrm{D}$ combustion chamber for a hydrogen-fuelled four-stroke internal combustion engine. CFD simulation has been carried out using commercial CFD codes. The engine speed was varied from 1000 to $3000 \mathrm{rpm}$, the range of equivalent ratio from 0.6 to 1.0 and the crank angle from 0 to 720 degrees in this study. The effect of the engine speed and equivalence ratio on the flow-field characteristics and volumetric efficiency are investigated in the motoring condition. The increase of engine speed gives a more efficient diffusion process for hydrogen and gives a more homogeneous air-fuel mixture structure. The characteristics of the flow-field are represented by the in-cylinder pressure and temperature distribution as well as the contours of the hydrogen mass fraction for different engine speeds. The acquired results show the maximum in-cylinder temperature and pressure obtained of $650 \mathrm{~K}$ and 1.143 $\mathrm{MPa}$ at the engine speed of $3000 \mathrm{rpm}$ respectively. It can be seen that the engine speed and equivalence ratio are strongly related to the volumetric efficiency. The results show that the volumetric efficiency increases linearly with increase of the engine speed, but decreases with increase of the equivalence ratio. The results obtained from the simulation can be employed to examine the homogeneity of the air-fuel mixture structure for a better combustion process and engine performance.
\end{abstract}

Keywords: Hydrogen fuel; CFD; equivalence ratio; in-cylinder; engine speed; volumetric efficiency.

\section{INTRODUCTION}

In today's world, where new technologies are being introduced every day, transportation's energy use is increasing rapidly. Fossil fuel and particularly petroleum fuel is the major contributor to energy production and the prime fuel for transportation[1-3]. Rapidly depleting reserves of petroleum and decreasing air quality raise questions about the future. Hydrogen, as an alternative fuel, has unique properties that give it significant advantages over other types of fuel [4-6]. Hydrogen can be used as a clean alternative to petroleum fuels and its use as a vehicle fuel is promising in the efforts to establish environmentally friendly mobility systems. So far, extensive studies have investigated hydrogen-fuelled internal combustion engines [7-12]. With increasing concern about energy shortages and environmental protection, and research on 
improving engine fuel economy, the hydrogen-fuelled engines are being developed with different methods for fuel supply [7, 8, 13-15]. Residue and pollution by emissions are produced as the growing number of vehicles on the road increases day by day. Hydrogen is particularly suitable for fuelling internal combustion engines [16-21]. Flow-field identification inside the cylinders of internal combustion engines during the intake, compression, expansion and exhaust strokes is an important stage for the understanding of the physical phenomena that occur in the motor cycle. The movement of the inlet air-fuel mixture in the cylinder has a great influence on the performance of the engine. So, the flow-field characteristics inside the cylinder of the internal combustion engine are attracting a lot of attention in automotive manufacturing and research and among researchers at the present time.

Developments in engine simulation technology have made the virtual engine model a realistic prospect [22]. Today, the use of CFD codes has developed and these codes can be used for engine simulation [23, 24]. The use of CFD in engine improvement programs has enabled significant time and cost savings to be made in the design and development of combustion engine systems [25]. Computational modelling and analysis of the flow in the cylinder is a major part of successful combustion, emission production and engine performance simulation. Realization of the in-cylinder flow pattern for the internal combustion engine is very substantial for advanced understanding and further optimization of the engine. The in-cylinder turbulent flow-field has a major influence on the combustion process, fuel consumption, emission production and engine performance. The main goal of this study is to model the fluid flow in a hydrogenfuelled internal combustion engine and investigate the in-cylinder flow characteristics utilizing CFD analysis. A dynamic simulation visualizing the flow-field characteristics in the case of a running engine will be performed. The effect of engine speed and the equivalence ratio on the in-cylinder flow-field characteristics and volumetric efficiency will be revealed.

\section{MATERIALS AND METHODS}

\section{Computational Modelling}

Internal combustion (IC) engine simulation is one of the most interesting topics in the field of computational fluid dynamics. CFD simulation was carried out on a twodimensional combustion chamber with piston, inlet and exit valves for the spark ignition engine. The engine specifications are tabulated in Table 1. The inlet and exhaust valve open and closed positions are expressed as the crank angle (CA). External mixture formation is achieved using several methods including the carburettor, which is considered in this study. Computational fluid dynamic modelling was developed utilizing the GAMBIT pre-processing software. The mesh was created utilizing triangular and quadrilateral elements with dynamic layering for the $2 \mathrm{D}$ model. The triangular elements are used where the geometry is complex and rapid transition from a fine mesh to coarse mesh is required, such as at the inlet and exit ports. On the other hand, the quadrilateral elements are used near geometries where the boundary moves in a linear direction. Thus the dynamic layers are used above the intake valve, exhaust valve and piston. The developed CFD model is shown in Figure 1. Further, the area above the valve has non-conformal interfaces. The purpose of such meshing and domain decomposition is to maximize the use of the layering method with the moving and deforming mesh (MDM) model. 


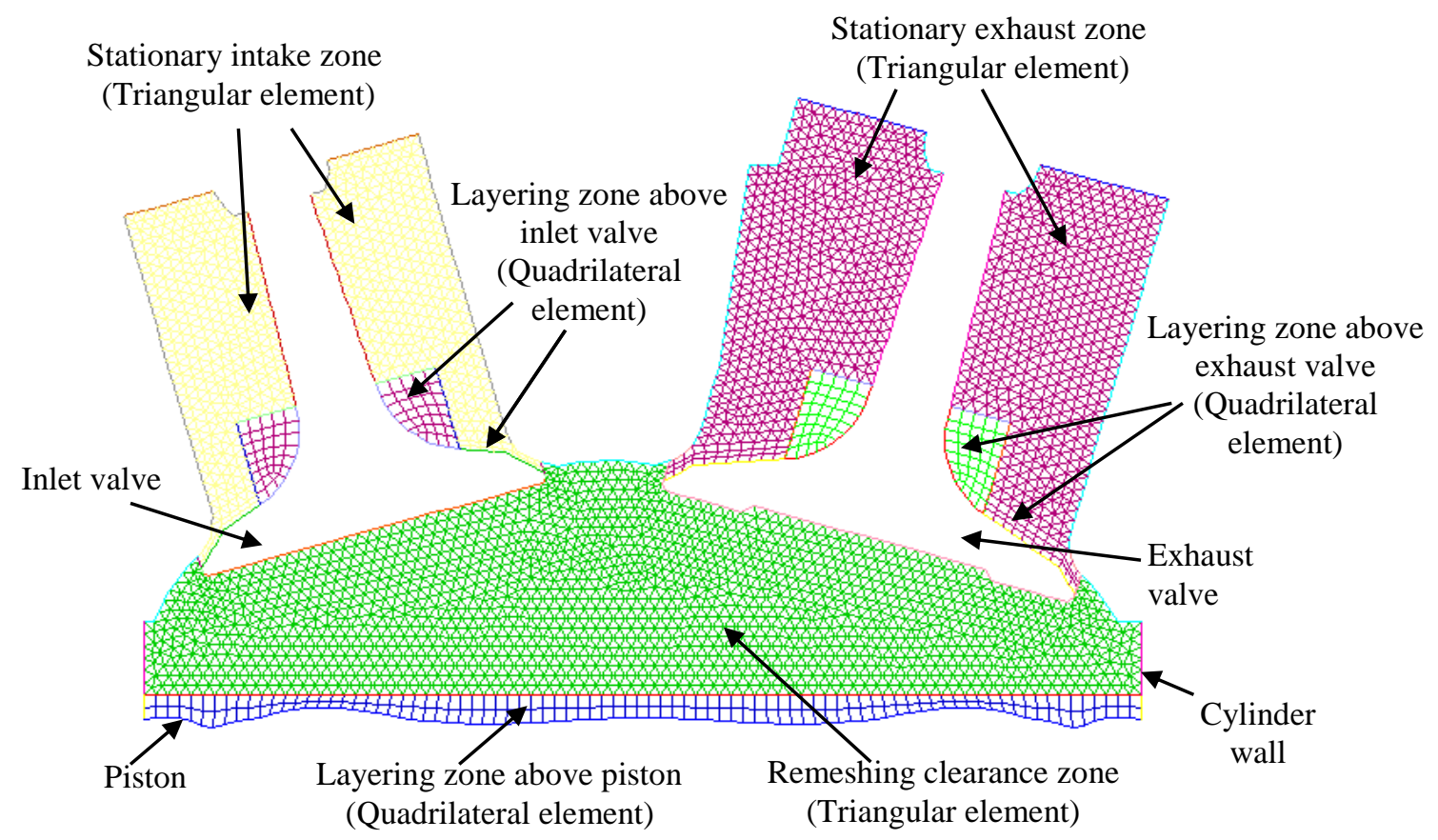

Figure 1. Computational dynamic model.

Table 1. Engine specifications.

\begin{tabular}{lll}
\hline Parameter & Value & Unit \\
\hline Bore & 88.00 & $\mathrm{~mm}$ \\
Stroke & 90.00 & $\mathrm{~mm}$ \\
Connecting rod length & 150.00 & $\mathrm{~mm}$ \\
Crank period & 720.00 & $\mathrm{CA}$ \\
Inlet valve open & 340.00 & $\mathrm{CA}$ \\
Exhaust valve open & 120.00 & $\mathrm{CA}$ \\
Inlet valve closed & 600.00 & $\mathrm{CA}$ \\
Exhaust valve closed & 360.00 & $\mathrm{CA}$ \\
Inlet valve diameter & 30.00 & $\mathrm{~mm}$ \\
Exhaust valve & 36.00 & $\mathrm{~mm}$ \\
diameter & & \\
Max. valve lift & $9.50 / 9.50$ & $\mathrm{~mm}$ \\
\hline \multicolumn{2}{c}{ CA = crank angle in degrees }
\end{tabular}

The dynamic mesh model was used to model flows where the shape of the domain is changing with time due to motion on the domain boundaries. Updating of the volume mesh is handled automatically by FLUENT at each time step based on the new positions of the boundaries [26]. The piston location as a function of the crank angle can be calculated to specify the piston stroke and connecting rod length. The piston location is expressed as in Eq. (1):

$$
p_{s}=L+\frac{A}{2}\left(1-\cos \theta_{c}\right)-\sqrt{L^{2}-\frac{A^{2}}{4} \sin ^{2} \theta_{c}}
$$


where $p_{s}$ is the piston position ( 0 at top dead centre (TDC) and $A$ at bottom dead centre (BDC), $L$ is the connecting rod length, $A$ is the piston stroke, and $\theta_{c}$ is the crank angle position.

The crank angle is calculated as in Eq. (2).

$$
\theta_{c}=\theta_{s}+t \Omega_{\text {shaft }}
$$

where $\theta_{\mathrm{s}} i$ is the starting crank angle and $\Omega_{\text {shaft }}$ is the crankshaft speed.

The dynamic model was updated based on layered quadrilateral elements and unstructured triangular elements. Stationary zones were maintained intact for each update. The valves motion is defined according to the profile that describes the variation of valve lift (in $\mathrm{mm}$ ) with the crank angle (in degrees). The valves lift profiles and the built-in functions describe how each surface moves as a function of the crank angle with respect to a reference point.

\section{Boundary and Initial Conditions}

The flow domain for simulation is the combustion chamber, including the inlet valve, exhaust valve, piston, intake port and exhaust port. Three types of boundary conditions have been used. The pressure-inlet boundary condition is used for the inlet to the intake port and the pressure-outlet boundary condition for the exit from the exhaust port, with the pressure setting for both of them as atmospheric pressure. The assumed values for the initial conditions are given in Table 2.

Table 2. Boundary and initial conditions.

\begin{tabular}{ll}
\hline Variable (unit) & Initial value \\
\hline Pressure $(\mathrm{pa})$ & Atmospheric pressure \\
X-velocity $(\mathrm{m} / \mathrm{s})$ & 0 \\
Y-velocity $(\mathrm{m} / \mathrm{s})$ & 0 \\
Turbulence kinetic energy $\left(\mathrm{m}^{2} / \mathrm{s}^{2}\right)$ & 0.01 \\
Turbulence dissipation rate $\left(\mathrm{m}^{2} / \mathrm{s}^{3}\right)$ & 0.01 \\
$\mathrm{H}_{2}$ concentration & 0 \\
Temperature $(\mathrm{k})$ & 318 \\
Cylinder wall temperature $(\mathrm{K})$ & 360 \\
Piston wall temperature $(\mathrm{K})$ & 360 \\
Valves wall temperature $(\mathrm{K})$ & 360 \\
Inlet pressure (pa) & Atmospheric pressure \\
Exhaust pressure $(\mathrm{pa})$ & Atmospheric pressure \\
\hline
\end{tabular}

\section{Model Formulation}

An integrated numerical model was developed for this study, permitting the mass, momentum and energy conservation equations to be solved in a time-dependent deforming $2 \mathrm{D}$ control volume. Besides these, the main governing equations for two additional sub-models are adopted in order to complete the simulation model. The $\kappa-\varepsilon$ turbulence model is considered to simulate the turbulent flow and fluctuation in the velocity field within the cylinder. The species model is used to represent the species transportation inside the domain without reaction between the fuel species. The fuel species of the air-hydrogen mixture is taken as the fuel model. Each of the governing 
equations and sub-model equations is solved according to the dynamic mesh conservation equations form [15].

The integral form of the conservation equation for a general scalar $(\Phi)$ on an arbitrary control volume $(V)$ moving boundary can be written as in Eq. (3):

$$
\frac{d}{d t} \int_{V} \rho \Phi d V+\int_{\partial V} \rho \Phi\left(\vec{u}-\vec{u}_{g}\right) \cdot d \vec{A}=\int_{\partial V} \Gamma \nabla \Phi \cdot d \vec{A}+\int_{V} S_{\Phi} d V
$$

where $\rho$ is the fluid density, $\vec{u}$ is the flow velocity vector, $\vec{u}_{g}$ is the grid velocity of the moving mesh, $\Gamma$ is the diffusion coefficient, $S_{\Phi}$ is the source term of $\Phi . \partial V$ is used to represent the boundary of the control volume.

The time derivative term in Eq. (3) can be written, using the first-order backward difference formula, as:

$$
\frac{d}{d t} \int_{V} \rho \Phi d V=\frac{(\rho \Phi V)^{n+1}-(\rho \Phi V)^{n}}{\Delta t}
$$

where $n$ and $n+1$ denote the respective quantity at the current and next time level. The $(n+1)$ th time level volume $V_{n+1}$ is computed from Eq. (5):

$$
V^{n+1}=V^{n}+\frac{d V}{d t} \Delta t
$$

where $d V / d t$ is the volume time derivative of the control volume.

In order to satisfy the grid conservation law, the volume time derivative of the control volume is computed by Eq. (6):

$$
\frac{d V}{d t}=\int_{\partial V} \vec{u}_{g} \cdot d \vec{A}=\sum_{j}^{n_{f}} \vec{u}_{g j} \cdot \vec{A}_{j}
$$

where ${ }_{n_{f}}$ is the number of faces on the control volume and $\vec{A}_{j}$ is the $j$ face area vector. The dot product $\vec{u}_{g j} \cdot \vec{A}_{j}$ on each control volume face is calculated by (7):

$$
\vec{u}_{g j} \cdot \vec{A}_{j}=\frac{\delta V_{j}}{\Delta t}
$$

where $\delta V_{j}$ is the volume swept out by the control volume face $j$ over the time step $\Delta t$.

The volumetric efficiency $\left(\eta_{v}\right)$ of the engine is to determine the effectiveness of the gas alternating process in a four-stroke engine. It defines the mass of air supplied through the intake valve during the intake period $\left(m_{a}\right)$, by comparison with a reference mass, which is that mass required to perfectly fill the swept volume under the prevailing atmospheric condition, and can be expressed as in (8): 


$$
\eta_{V}=\frac{m_{a}}{\rho_{a} V_{d}}
$$

where $\rho_{a}$ is the inlet air density and $V_{d}$ is the swept volume.

The volumetric efficiency has been adopted in this study. The volumetric efficiency of the engine can be determined by approximating the 2D inlet into a 3D inlet considering the analysis geometry per unit depth. From the mass flow history of the inlet valve,

Total volume of the air injected into the cylinder $=\frac{\text { Mass flow rate } \times \text { time of flow }}{\text { air density }}$

$$
=\frac{\text { Area under mass flow history at inlet manifold }}{\text { air density }}
$$

Hence, $\eta_{\mathrm{v}}=\frac{\text { Area under mass flow history at inlet manifold }}{\text { air density } \times \text { swept volume }}$

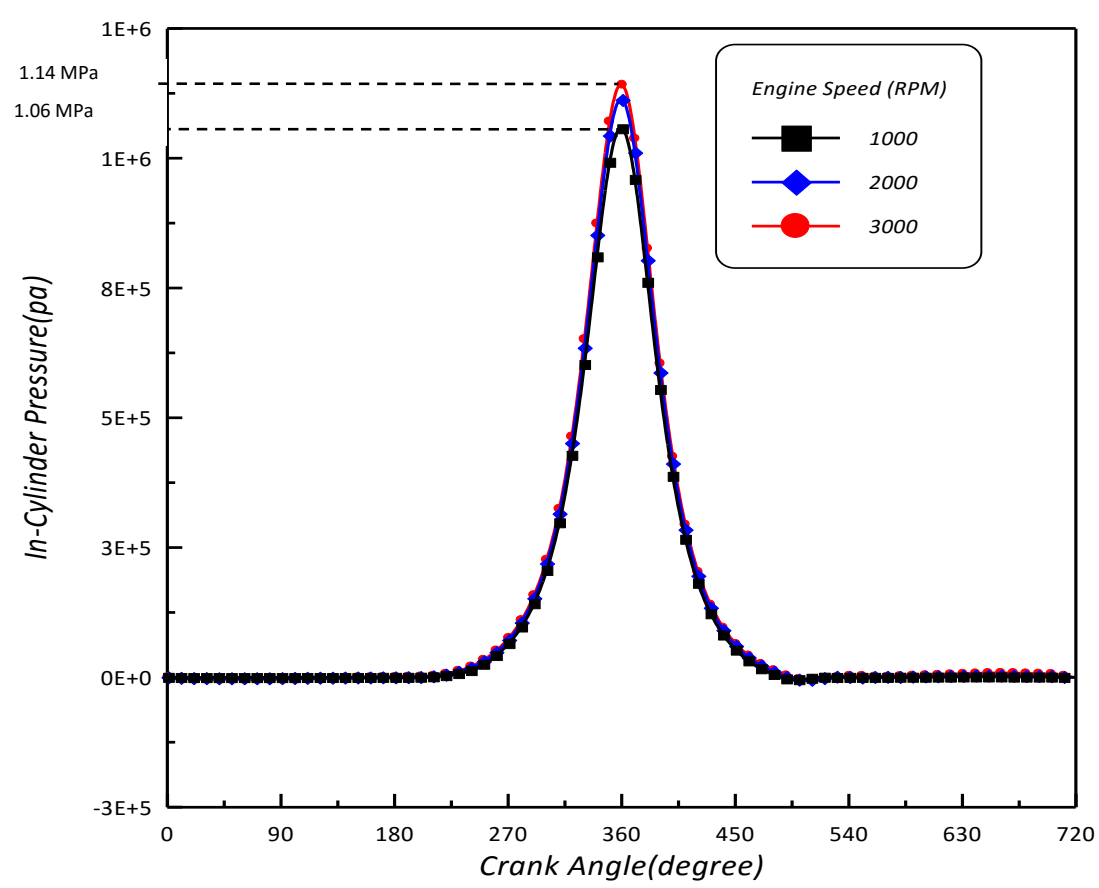

Figure 2. Variation of in-cylinder pressure against crank angle with different engine speeds.

\section{RESULTS AND DISCUSSION}

\section{Variation of In-cylinder Pressure and Temperature}

The variation of the in-cylinder pressure against the crank angle with different engine speeds is shown in Figure 2. It can be seen that the in-cylinder pressure increases with increase of the engine speed. The maximum in-cylinder pressures of $1.143 \mathrm{MPa}$ and $1.06 \mathrm{MPa}$ are obtained at $3000 \mathrm{rpm}$ and $1000 \mathrm{rpm}$ respectively. The difference is clearer at TDC, which is the peak pressure location. According to the equation of state for the ideal gas, the temperature variation is a function of the pressure. Temperature variation 
inside the cylinder also shows an identical pattern to the pressure profile. The variation of in-cylinder temperature against crank angle is shown in Figure 3. It can be seen that the maximum temperature is obtained at the higher engine speed. The maximum temperature for $3000 \mathrm{rpm}$ is $650 \mathrm{~K}$, whereas for $1000 \mathrm{rpm}$ it is $636 \mathrm{~K}$. For all the aforementioned cases, the maximum temperature is obtained after attaining the peak pressure.

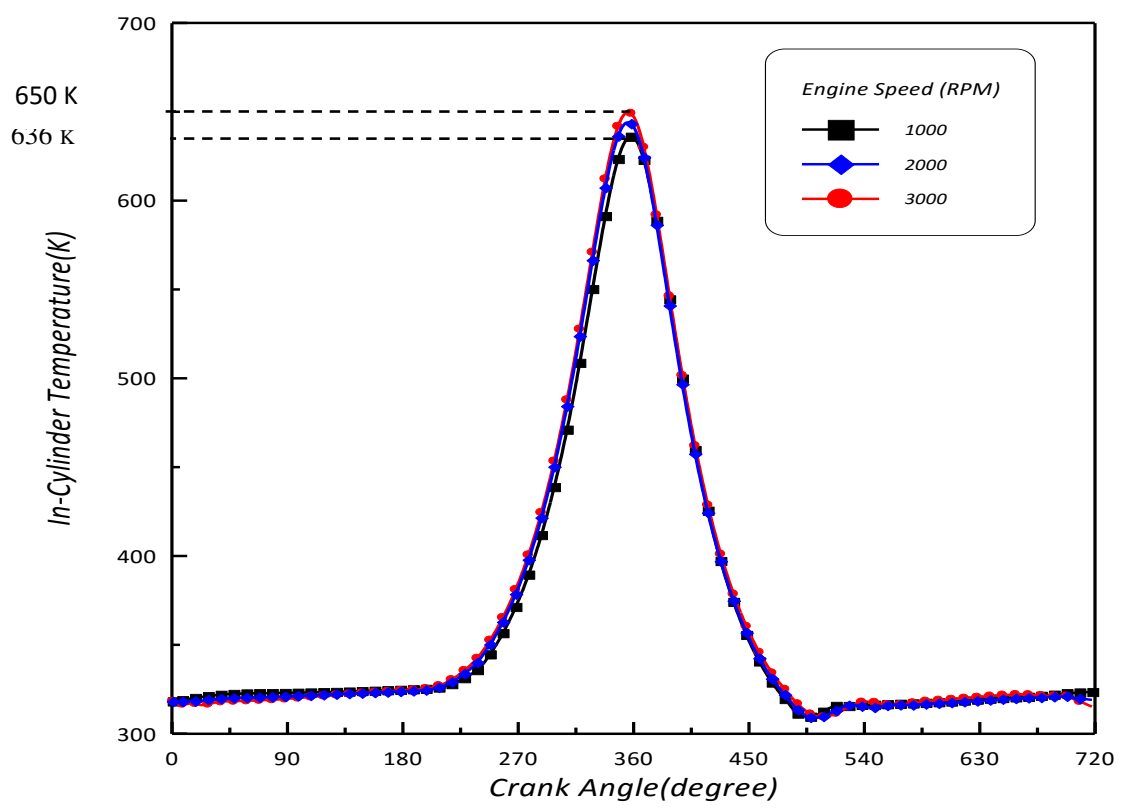

Figure 3. Variation of in-cylinder temperature against crank angle with different engine speeds.

Maximum mass concentration obtained $0.0144 \%$ at intake port region

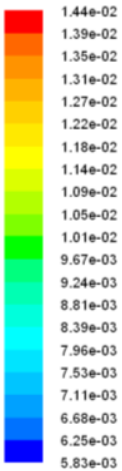

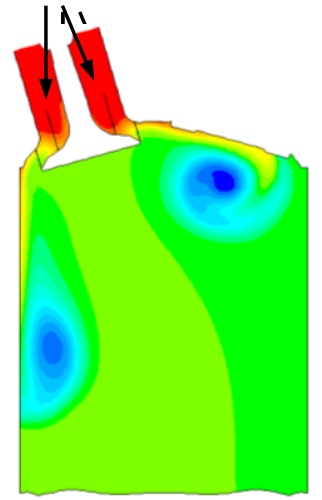

(a) Crank angle at $540^{\circ}$
Maximum mass concentration obtained $0.0111 \%$ at inlet region for intake port
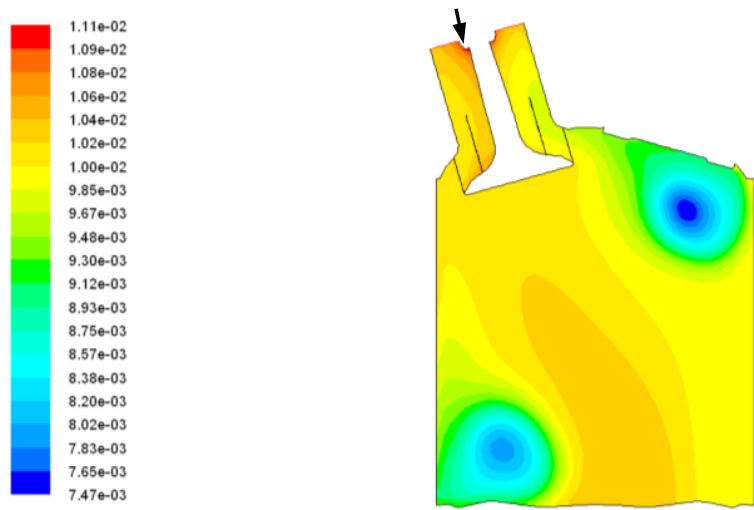

(b) Crank angle at $585^{\circ}$

Figure 4. Variation of hydrogen mass fraction.

\section{Variation of Hydrogen Mass Concentration}

The progress of hydrogen diffusion inside the domain is illustrated in Figure 4. Two locations, i.e. the crank angle at $540^{\circ}$ and $585^{\circ}$ of ATDC, are selected to show the 
diffusion process for the hydrogen species inside the simulation domain during the intake phase. It is shown that, at the beginning, the hydrogen species still has a limited distribution only at the intake port, which is very intensive with hydrogen. The progress of the diffusion process gradually increases as the crank angle increases [27-29]. The effect of the engine speed on the hydrogen species concentration inside the domain of simulation during the intake phase is shown in Figure 5. It can be seen that the increases in the engine speed give a more efficient diffusion process for the hydrogen and greater homogeneity of the air-fuel mixture structure due to increase of the vacuum pressure inside the combustion chamber.

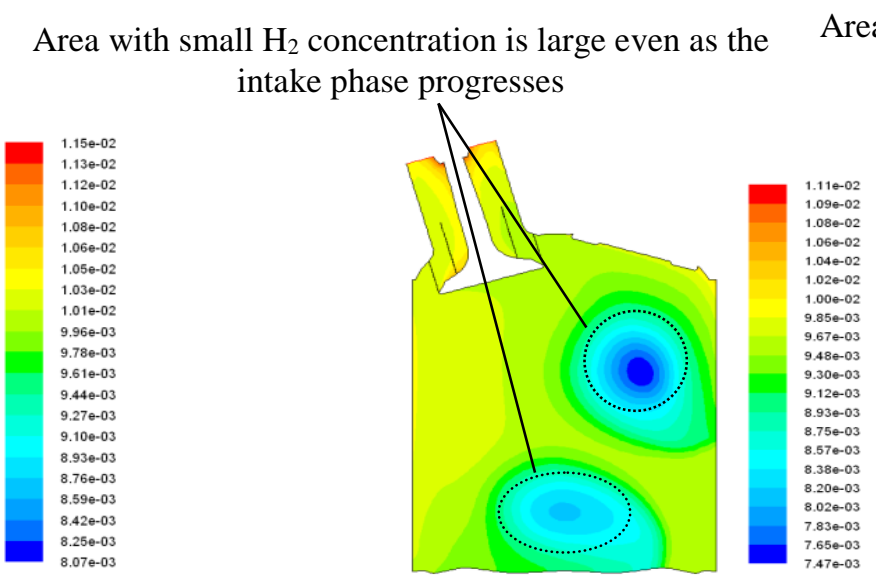

(a) $1000 \mathrm{rpm}$
Area with small $\mathrm{H}_{2}$ concentration is decreased for the same stage of the intake phase

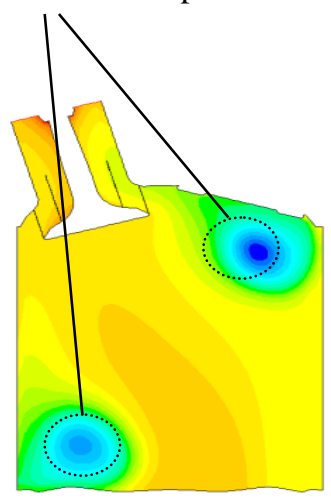

(b) $2000 \mathrm{rpm}$

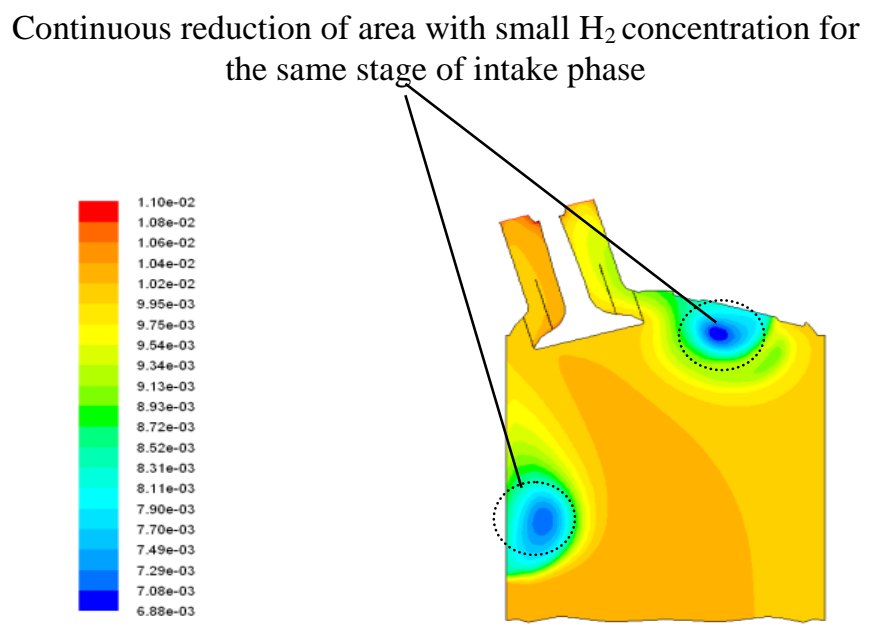

(c) $3000 \mathrm{rpm}$

Figure 5. Hydrogen mass fraction for different engine speeds.

\section{Variation of Volumetric Efficiency}

Figure 6 shows the volumetric efficiency variation with respect to the engine speed and equivalence ratio. In general, it is desirable to have the maximum volumetric efficiency for an engine. The importance of volumetric efficiency is more critical for a hydrogen engine because the hydrogen fuel displaces a large amount of the incoming air due to its low density $\left(0.0824 \mathrm{~kg} \mathrm{~m}^{-3}\right.$ at $25^{\circ} \mathrm{C}$ and $\left.1 \mathrm{~atm}\right)$. This reduces the volumetric efficiency 
to a great extent [30]. It can be seen that the volumetric efficiency decreases with increase of the equivalence ratio for the particular engine speed. This is expected because increase of the equivalence ratio leads to increasing the amount of hydrogen in the charge and that means a decrease in the amount of air which enters the combustion chamber per cycle. Meanwhile, the volumetric efficiency increases with increase of the engine speed for all equivalence ratios. This is due to increase of the vacuum at the intake port as the engine speed increases. Hence the large amount of air that is drawn into the cylinder.

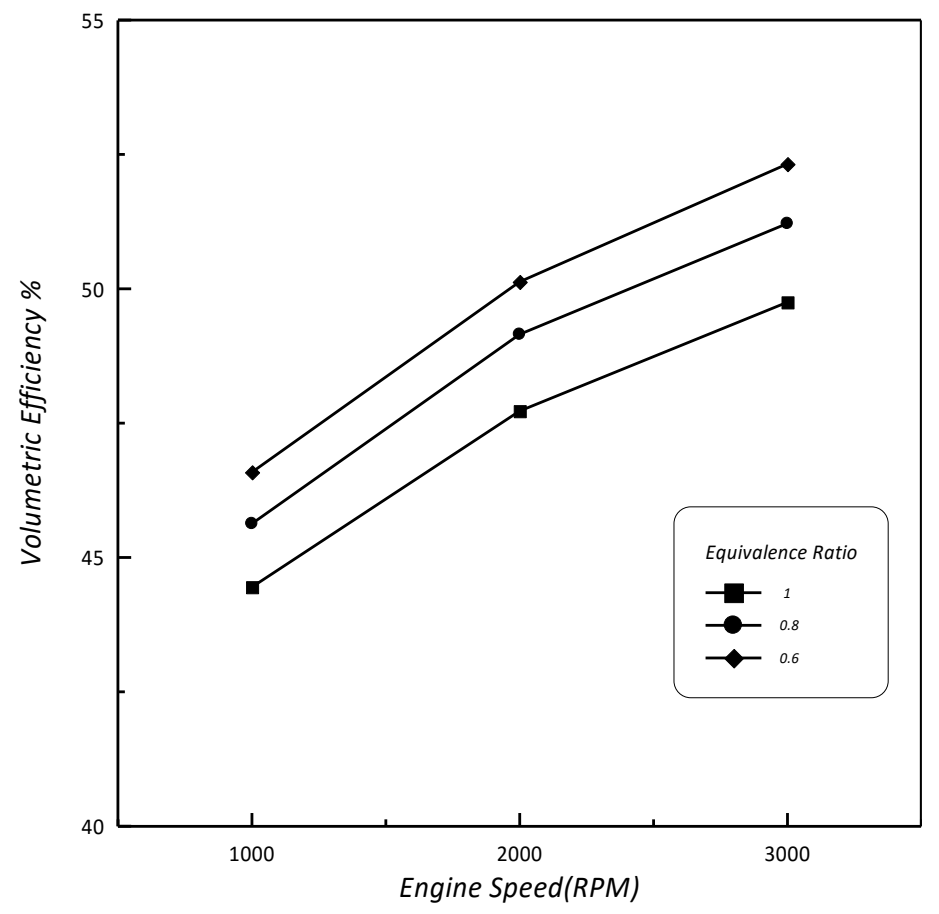

Figure 6. Variation of volumetric efficiency against engine speed and equivalence ratio.

\section{CONCLUSIONS}

A detailed CFD model to predict the flow-field characteristics and volumetric efficiency was developed. The results obtained from the simulation can be employed to examine the homogeneity of the air-fuel mixture structure for a better combustion process and engine performance. The results have been achieved by using dynamic simulations for a better understanding of the processes in the hydrogen-fuelled internal combustion engine, paving the way for further research on this topic. The simulation can be extended with other subjects such as injection and combustion to obtain a complete model of the hydrogen-fuelled internal combustion engine.

\section{ACKNOWLEDGMENTS}

The authors would like to thanks University Malaysia Pahang for provides laboratory facilities and financial support under project no. RDU1403126. 


\section{REFERENCES}

[1] Hairuddin AA, Wandel AP, Yusaf T. An introduction to a homogeneous charge compression ignition engine. Journal of Mechanical Engineering and Sciences. 2014;7:1042-52.

[2] Kamil M, Rahman MM, Bakar RA. Performance evaluation of external mixture formation strategy in hydrogen fueled engine. Journal of Mechanical Engineering and Sciences. 2011;1:87-98.

[3] Hamada KI, Mohammed MK, Rahman MM. Development of a test-rig for a modern motorcycle engine. International Journal of Automotive and Mechanical Engineering. 2014;10:2034-41.

[4] Kamil M, Rahman MM. Effect of injection hole diameter on operational conditions of common-rail fuel-injection system for port-injection hydrogenfueled engine. International Journal of Automotive and Mechanical Engineering. 2015;11:2383-95.

[5] Kamil M, Rahman MM, A. Bakar R. An Integrated model for predicting engine friction losses in internal combustion engines. International Journal of Automotive and Mechanical Engineering. 2014;9:1695-708.

[6] Kamil M, Rahman MM, Bakar RA. Integrated simulation model for composition and properties of gases in hydrogen fueled Engine. International Journal of Automotive and Mechanical Engineering. 2013;8:1242-155.

[7] White C, Steeper R, Lutz A. The hydrogen-fueled internal combustion engine: a technical review. International journal of hydrogen energy. 2006;31:1292-305.

[8] Kahraman E, Ozcanlı SC, Ozerdem B. An experimental study on performance and emission characteristics of a hydrogen fuelled spark ignition engine. International journal of hydrogen energy. 2007;32:2066-72.

[9] Rahman M, Mohammed MK, Bakar RA. Effects of engine speed on injection timing and engine performance for 4-cylinder direct injection hydrogen fueled engine. Canadian Journal of Pure and Applied Sciences. 2009;3:731-9.

[10] Hasan MM, Rahman MM, Kadirgama K. A Review on homogeneous charge compression ignition engine performance using biodiesel-diesel blend as a fuel. International Journal of Automotive and Mechanical Engineering. 2015;11:2199-211.

[11] Azad AK, Rasul MG, Mofijur M, Bhuiya MMK, Mondal SK, Sattar MK. Energy and waste management for petroleum refining effluents: a case study in Bangladesh. International Journal of Automotive and Mechanical Engineering. 2015;11:2170-87.

[12] Azad AK, Rasul MG, Giannangelo B, Islam R. Comparative study of diesel engine performance and emission with soybean and waste oil biodiesel fuels. International Journal of Automotive and Mechanical Engineering. 2015;12:2866-81.

[13] Lee JT, Kim Y, Caton JA. The development of a dual injection hydrogen fueled engine with high power and high efficiency. ASME 2002 Internal Combustion Engine Division Fall Technical Conference: American Society of Mechanical Engineers; 2002. p. 323-33.

[14] Rahman M, Mohammed MK, Bakar RA. Effects of air fuel ratio and injection timing on performance for four-cylinder direct injection hydrogen fueled engine. European Journal of Scientific Research. 2009;25:214-25. 
[15] Ramasamy D, Zainal ZA, Kadirgama K, Walker-Gitano Briggs H. Effect of dissimilar valve lift on a bi-fuel CNG engine operation. Energy. 2016;112:50919.

[16] Yusaf T, Yusoff MZ, Hussein I, Fong S. A quasi one-dimensional simulation of a 4 stroke spark ignition hydrogen fuelled engine. American Journal of Applied Sciences. 2005;2:1206-12.

[17] Kamil M, Rahman MM. Performance prediction of spark-ignition engine running on gasoline-hydrogen and methane-hydrogen blends. Applied Energy. 2015;158:556-67.

[18] Kamil M, Rahman MM. Effect of injection hole diameter on operational conditions of common-rail fuel-injection system for portinjection hydrogenfueled engine. International Journal of Automotive and Mechanical Engineering. 2015;11:2383-95.

[19] Hamada KI, Rahman MM, Abdullah MA, Bakar RA, A. Aziz AR. Effect of mixture strength and injection timing on combustion characteristics of a direct injection hydrogen-fueled engine. International Journal of Hydrogen Energy. 2013;38:3793-801.

[20] Rahman MM, Hamada KI, Bakar RA, Maleque MA. Heat transfer analysis inside exhaust port for a hydrogen fueled port injection engine. Advanced Science Letters. 2012;14:239-43.

[21] Hamada KI, Rahman MM, Aziz ARA. Multidimensional computational modeling of direct injection for hydrogen fueled engine. Advanced Science Letters. 2012;13:317-21.

[22] Li G, Sapsford S, Morgan R. CFD simulation of a DI truck engine using Vectis. SAE, Paper; 2000.

[23] Khalighi B, Haworth DC, Huebler MS. Multidimensional port-and-in-cylinder flow calculations and flow visualization study in an internal combustion engine with different intake configurations. SAE Technical Paper; 1994.

[24] Godrie P, Zellat M. Simulation of flow field generated by intake port-valvecylinder configurations-comparison with measurements and applications. SAE Technical Paper; 1994.

[25] Shojaeefard M, Noorpoor A. Flow simulation in engine cylinder with spring mesh. American Journal of Applied Sciences. 2008;5:1336-43.

[26] FLUENT TG. Modeling External Compressible Flow. Fluent Inc. 2003.

[27] Ramasamy D, Kadirgama K, Rahman MM, Zainal ZA. Analysis of compressed natural gas burn rate and flame propagation on a sub-compact vehicle engine. International Journal of Automotive and Mechanical Engineering. 2015;11:2405-16.

[28] Kim Y, Lee JT, Choi GH. An investigation on the causes of cycle variation in direct injection hydrogen fueled engines. International Journal of Hydrogen Energy. 2005;30:69-76.

[29] Ramasamy D, Bakar RA, Rahim MF, Noor MM. Comparative evaluation of a two stroke compressed natural gas mixer design using simulation and experimental techniques. Proceedings of the 4th IASTED Asian Conference on Power and Energy Systems, Asia. 2008; p. 359-62.

[30] Rahman M, Mohammed MK, Bakar RA. Effects of air fuel ratio and engine speed on engine performance of hydrogen fueled port injection engine. American Journal of Scientific Research. 2009;1:23-33. 